\title{
幍H90
}

\section{Fuente Obejuna y el teatro}

\author{
Manuel Gahete Jurado | cronista oficial de Fuente Obejuna \\ URL de la contribución <www.iaph.es/revistaph/index.php/revistaph/article/view/3842>
}

\section{RESUMEN}

Los hallazgos arqueológicos descubiertos en el entorno municipal de Fuente Obejuna y las catorce aldeas de su jurisdicción nos remiten a un pasado digno de estudio que aún no ha sido afrontado. Lo que podemos aseverar como hecho demostrable es que la noble villa cordobesa irrumpe en el escenario de la historia, teñida de leyenda, con la publicación de la obra dramática Fuenteovejuna, del insigne escritor madrileño Félix Lope de Vega Carpio, conocido como el Fénix de los Ingenios Españoles. En este momento, la dimensión histórica de Fuente Obejuna cobra aliento épico convirtiéndose en el referente inequívoco del teatro político y alcanzando difusión internacional.

Fuente Obejuna nunca ha estado ajena a esta realidad que convierte al pueblo cordobés en adalid de la rebelión contra el comendador mayor de Calatrava Fernán Gómez de Guzmán, representante literario por antonomasia del omnipotente feudalismo que, a la luz de esta gesta, comienza a resquebrajarse en favor del poder real. Aunque ciertamente son muchas las circunstancias conniventes que propician la transición del medioevo a la Edad Moderna, será la caída del régimen feudal uno de los paradigmas esenciales. La aproximación científica que permite establecer relaciones entre la historia y la literatura fijará la obra de Fuenteovejuna como el eje transicional inequívoco de que un nuevo tiempo histórico se estaba originando. Esta virtualidad reconocible, unida a la poderosa atracción de los personajes creados por Lope, litigando por su dignidad en nombre del amor y la justicia, nos obligan sin tregua a mirarnos en el espejo claro de nuestra heroica identidad.

\section{Palabras clave}

Córdoba (Provincia) | Fuente Obejuna | Fuenteovejuna | Historia | Lope de Vega Carpio, Félix de | Representación teatral | Política | Teatro | 


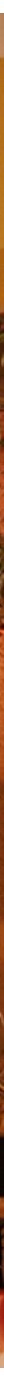

Representación de Fuenteovejuna del año 2009 | foto Manolo Blanca 

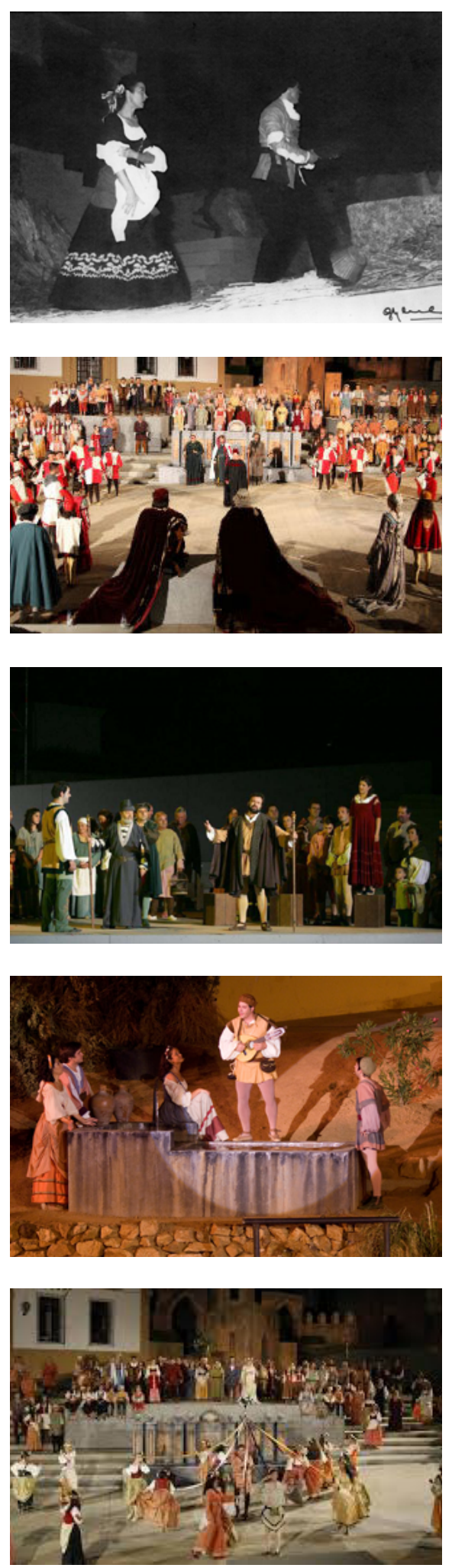

En 1618 se editaba en Madrid la obra Fuenteovejuna, inserta en el volumen Dozena Parte de las Comedias de Lope de Vega. El escritor y crítico santanderino Marcelino Menéndez Pelayo afirmará que se trata de una obra inmortal y que no hay otra "más democrática en todo el teatro caste\|lano" (1899). Muchos años después el senador socialista Joaquín Martínez Bjorkman, en las Primeras Jornadas de la Real Academia de Córdoba en Fuente Obejuna, dejará escrito que la obra constituye "una distinta manera de mostrar un teatro político comprometido" $(1996,144)$. Aunque los orígenes del teatro político se pierden en los textos más antiguos de la tragedia griega, en los que democracia y educación se integraban como vectores coadyuvantes (HERRERAS, 2009: 9), lo cierto es que, con Bertolt Brecht y Erwin Piscator, el teatro épico o documental cobra su capital relevancia (ALDEKOA, 2016). El teatro político va a convertirse en el manifiesto más notorio contra un statu quo ajeno a la realidad humana, poniendo ante los ojos del espectador la injusticia de un mundo atormentado por los jinetes del apocalipsis. Aunque el tema del honor, unido al del amor verdadero, recorre transversalmente Fuenteovejuna, será el argumento de las disputas de poder entre los partidarios de Isabel la Católica y Juana la Beltraneja el que articule la acción. Los desmanes de la guerra van a convertir al antes noble y valiente comendador en un ser despiadado que pretende resarcirse de la vergüenza de su derrota en los indefensos súbditos, despertando el espíritu libertario de responsabilidad copartícipe del que la obra lopesca está inflamado y convirtiendo este poder colectivo en el personaje coral más importante de toda la dramaturgia española.

Los hechos que describe Fuenteovejuna ocurrieron hace quinientos cuarenta años (1476-2016) pero la defensa de la dignidad que representa sigue siendo ejemplo y luz para las nuevas generaciones. Basada en un controvertido hecho histórico acaecido durante el reinado de los Reyes Católicos y protagonizado por el pueblo cordobés de Fuente Obejuna, que se solidariza unánimemente para acabar con los ultrajes del comendador calatraveño, trasciende el plano local para convertirse en clave de la victoria de la monarquía sobre el desgastado feudalismo y la unificación territorial bajo la autoridad de los Reyes Católicos; y, aún más, cobra la virtualidad ecuménica de presentarnos a los habitantes de la villa melariense como protagonista colectivo, alcanzando la categoría de símbolo: la fuerza de la unión de los más débiles contra el felón atropello de los poderosos. Otros análisis nos llevarían asimismo a proclamar la autoridad del pueblo soberano, capaz de desafiar los poderes institucionales y vencerlos con el argumento más humano de la solidaridad frente a la injusticia.

Lope de Vega escribió su obra casi ciento cincuenta años después de que ocurrieran los hechos que relata, acogiéndose a los documentos escritos por Alonso de Palencia (1423-1492), primer cronista real de Enrique IV y más tarde cronista oficial en el reinado de Isabel I. En su monumental obra Gesta 


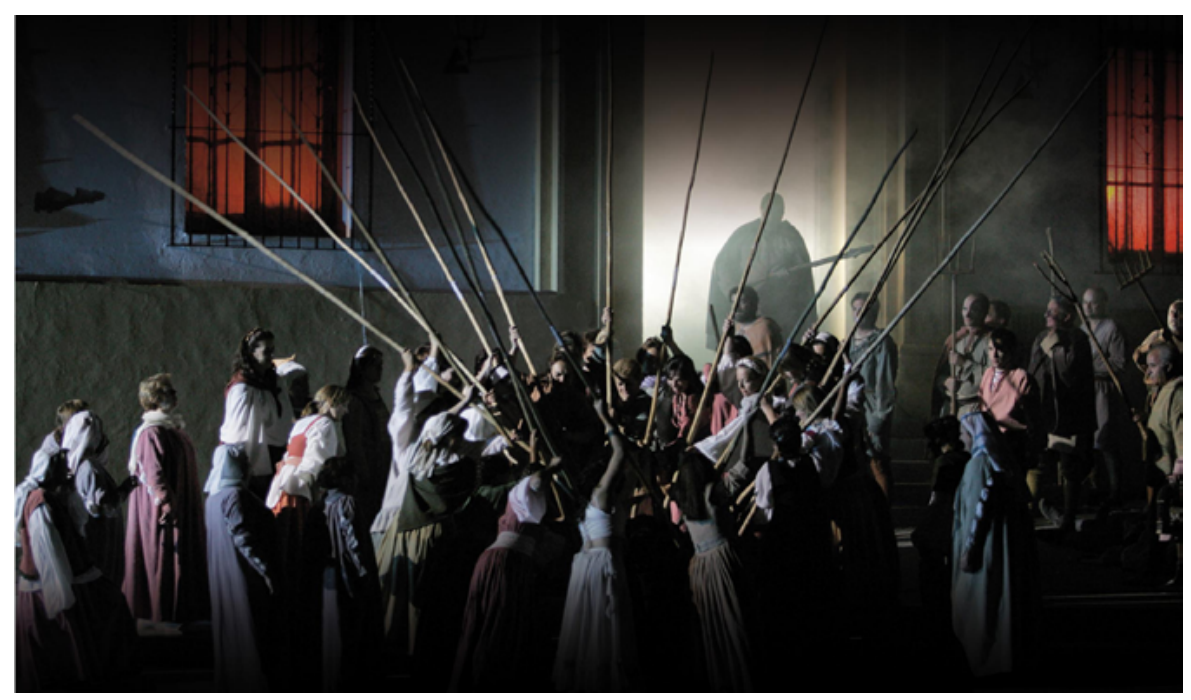

Hispaniensia ex annalibus suorum diebus colligentis, dividida en décadas al estilo de Tito Livio, Palencia afirma que Fernán Gómez de Guzmán es un noble comendador, leal a los reyes, y su muerte un crimen abominable. Más se acerca a la versión lopesca la Chrónica de las tres Órdenes y Caballerías de Santiago, Calatrava y Alcántara, escrita en 1572 por Francisco de Rades y Andrada y conservada en la Biblioteca Nacional de Madrid (ms. 3.269 en los folios 331-332). El padre Mariana, en su Historia General de España (1601), coincide con Rades en subrayar la tiranía del comendador mayor de Calatrava y su adicción a la causa portuguesa de Juana la Beltraneja, contraria a la facción de Isabel. Otros documentos consultados por Lope debieron ser el caso número 21 ("La muerte del Comendador Mayor de Calatrava"), en los libros Casos raros de Córdoba (Biblioteca de la Real Academia de la Historia) y Tesoro de la lengua castellana de Sebastián de Covarrubias, impreso en el año 1611. Es poco probable que Lope estuviera al tanto de la Historia de Córdoba de Andrés Morales y Padilla, editada el mismo año en que lo fue su obra Dozena Parte de las Comedias de Lope de Vega (1618). Mucho más creíble es pensar que el episodio heroico del "iTodos a una!" fuera conocido por la gente del pueblo, difundido en las narraciones y romances de los cantares de ciego y la literatura de cordel, tan populares en la época, intuyendo el agudo Lope, acérrimo detractor de estos troveros a los que tildaba de corta ilustración literaria (AMEZCUA, 1991), que tan seductor argumento debía atraer el interés y la fascinación de los expectantes oyentes. Porque la distancia temporal no priva al drama Fuenteovejuna de poderosa actualidad en la época de su publicación. En España se había afirmado la monarquía absoluta, aunque el poder que representaba Felipe II comenzaba a desmoronarse en sus sucesores Felipe III y Felipe IV, que dejaron su gobierno en manos de ambiciosos validos, llevando a España hacia una guerra que acabó con el imperio de los Austrias e implantó la dinastía bor-

Representación de Fuenteovejuna en años distintos fotos p. 94 (de arriba a abajo): 1956 (Ayuntamiento de Fuente Obejuna); 2013 (Manolo Blanca); 2006 (Francisco J. Cabezas); 2009 (Manolo Blanca); 2013 (Manolo Blanca); página 95: 2006 (José Carlos Nieva) 


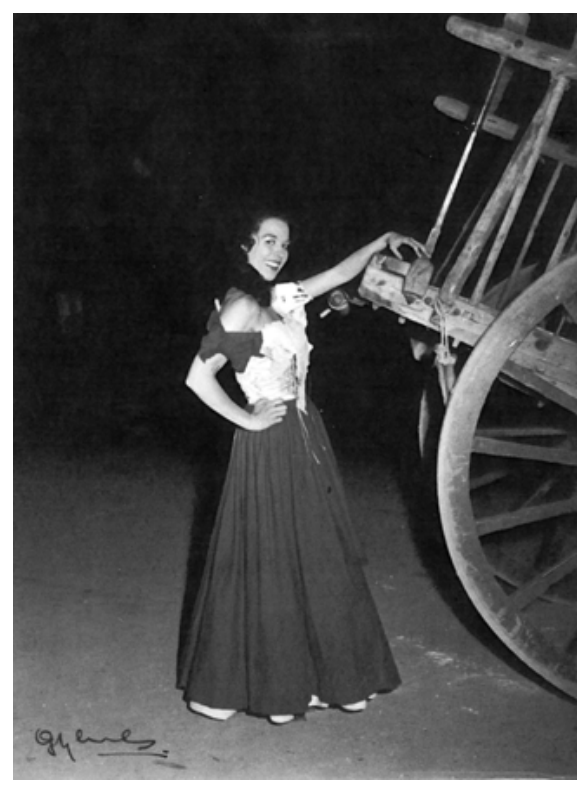

Representación del 1956 protagonizada por Aurora Butista | foto Ayuntamiento de Fuente Obejuna bónica que aún perdura. Lope de Vega siempre defendió el sistema político monárquico imperante en su tiempo, por lo que no tuvo que esforzarse para representar a los Reyes Católicos como poderosos y competentes fautores de un justo concepto del Estado, defensores vigorosos de una nación que se afirmaba contra las potencias extranjeras y fundadores de la gran España imperial; y era asimismo consciente de que el público -que sufría y disfrutaba con sus representaciones- participaba de aquellas mismas ideas en el ámbito de un patrimonio ideológico común (FROLDI, 2002).

En la trama de Fuenteovejuna alternan dos planos claramente identificados: el histórico-político y el social-amoroso. Son varias las motivaciones históricas -expuestas por diferentes estudiosos y analistas- que llevan al pueblo de Fuente Obejuna a rebelarse contra el comendador, al que acusan de robar a los pobladores hacienda y honor, elemento cardinal en la mayoría de las obras dramáticas del Siglo de Oro. Lope apuesta por considerar que, tras el pretexto del abuso sexual del comendador mayor de Calatrava a la bragada Laurencia, la rebelión tiene como fondo la lucha del partido de Juana la Beltraneja con los partidarios de Isabel la Católica, a cuya autoridad el pueblo se pliega finalmente. Pero son otras las causas apuntadas por los historiadores para argumentar este levantamiento, más cercanas a la población melariense, atribuibles a la presión externa del alfoz de Córdoba, cuyos mandatarios recelaban del comendador, y del cabildo catedralicio a los que hurtaba sus diezmos y escandalizaba con su promiscuidad. Sea como fuere, la idea capital que se desprende de esta obra magna, arquetipo de la reivindicación del oprimido frente al despotismo del opresor, es la unidad frente a la injusticia que magnifica, difunde y eterniza el valor de un pueblo sometido por la crueldad de un tirano. Lope de Vega articula con singular maestría estos núcleos temáticos aparentemente desconectados configurando una obra perfectamente estructurada en su complejidad, lo que permite explicar al espectador los hechos sin desvirtuar el sentido de proclama política y reivindicación de las libertades, fusionando en un poderoso personaje colectivo toda la tensión dialéctica que supone la lucha de clases y los conflictos de poder. Es curioso detectar, sin embargo, que la obra tuvo inicialmente poca fortuna, aun cuando los conflictos entre la aristocracia feudal y los reyes permanecían vigentes; y las órdenes religioso-militares, como la de Calatrava, seguían manteniendo posturas de confrontación con los soberanos. El público no desconocía que los abusos de poder y las prevaricaciones de muchos de sus miembros no eran cuestiones del pasado. A ello debía sumarse la legítima ambición de una clase social emergente como era la de los labradores, representados perfectamente en Fuenteovejuna, que reclamaban una posición ascendente que los acercara a la nobleza. A pesar de la actualidad de estos hechos y que la monarquía veía en ellos un eficaz apoyo a su política, no se tienen noticias fehacientes de que la obra fuera representada con asiduidad en tiempos de Lope ni tampoco posteriormente (FROLDI, 2002). Habrá que esperar al siglo XIX para encontrar la primera reimpresión 
de la obra. Será en este siglo de intensa industrialización y permanentes reivindicaciones sociales cuando Fuenteovejuna comience a cobrar fuerza de nuevo para alcanzar en el siglo XX una amplia difusión, siendo leída y representada con renovable frecuencia en España (no solo en los escenarios sino en la televisión y el cine), convirtiéndose -como se ha reiterado- en símbolo universal.

El pueblo al que representa nunca se ha sentido ajeno a este potencial cultural y sociopolítico. Conocedor del legado que Lope de Vega nos transmitió en el siglo XVII, por el que somos probablemente uno de los pueblos del mundo sobre el que más páginas se han vertido, acogemos su representación con regularidad desde el año 1992, aunque debamos retrotraer nuestra memoria a las representaciones anteriores: los días 23, 24 y 25 de agosto de 1935, conmemorando el III centenario de la muerte de Lope de Vega, la compañía de Enrique Borrás y Margarita Xirgu representó en la plaza principal de Fuente Obejuna la obra homónima. La compañía Lope de Vega, dirigida por José Tamayo, pondrá en escena la obra, el 5 de julio de 1956, en la plaza del pueblo, legándonos la magistral interpretación de Aurora Bautista en el papel de Laurencia. Será la misma compañía la que regresará a Fuente Obejuna, con motivo de cumplirse el IV centenario del nacimiento de Lope de Vega (1562-1962), para representarla el 28 de junio al 1 de julio, siendo José Osuna el encargado de la dirección y Analía Gadé la actriz protagonista.

Habrá que esperar treinta años para que Fuenteovejuna vuelva a representarse, ahora por los naturales de la villa, en el mes de agosto de 1992. Presidía entonces el concejo de la villa el alcalde Pedro Fernández Mahedero. María Paz Ballesteros, con versión de Enrique Llovet, dirigirá esta representación y asimismo la siguiente de 1994, en esta ocasión adaptada por Rafael Pérez Sierra. Sucesivamente se irán relevando en la dirección Javier Osorio (1997 y 2004), Fernando Rojas (2000 y 2009), Emilio Goyanes (2006) y Manuel Canseco (2013). En este año 2016, por vez primera en la historia del teatro en Fuente Obejuna, además de los actores, la dirección se encarga a un melariense, Ángel Luis Martín, y la versión corre a cargo de Manuel Gahete, también natural de la villa, de la que es cronista oficial. Materia prima autóctona por los cuatro costados. Tanto Martín como Gahete, entre otros, representan el espíritu luchador y abnegado del pueblo de Fuente Obejuna hacia el teatro, interviniendo enérgicamente en todas las acciones que han propiciado custodiar el fuego siempre vivo del arte dramático, congénito a la naturaleza de los melarienses, pegado a su piel. Martín desde los grupos de teatro, que han sido y siguen siendo factores cruciales de la cultura melariense. Gahete al frente del Certamen de Teatro Fuenteovejuna, iniciado en el año 1984, con el indispensable patrocinio del Ayuntamiento, regido entonces por el alcalde José Mellado Benavente, y la colaboración de la Delegación Provincial de Cultura de la Junta de Andalucía. Nos movía la necesidad de divulgar el legado del pueblo de Fuente Obejuna y sus catorce

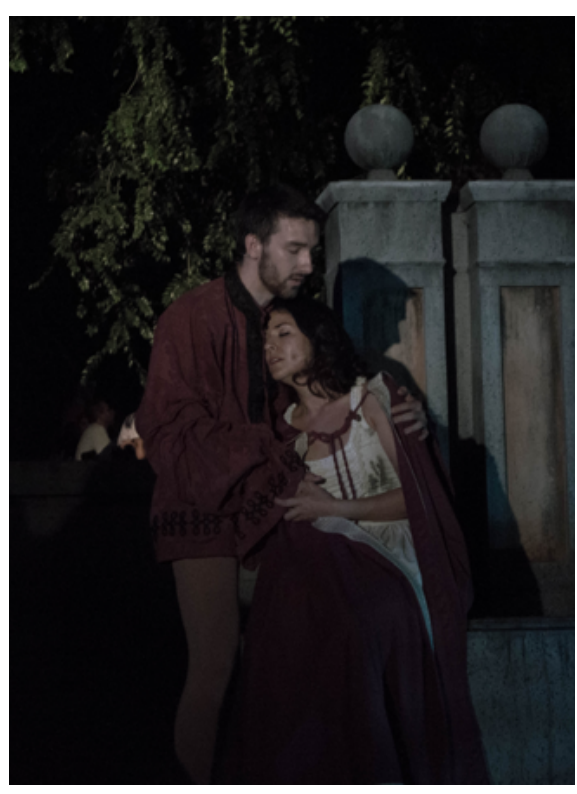

Representación del año 2015 | foto Cristina Martín 

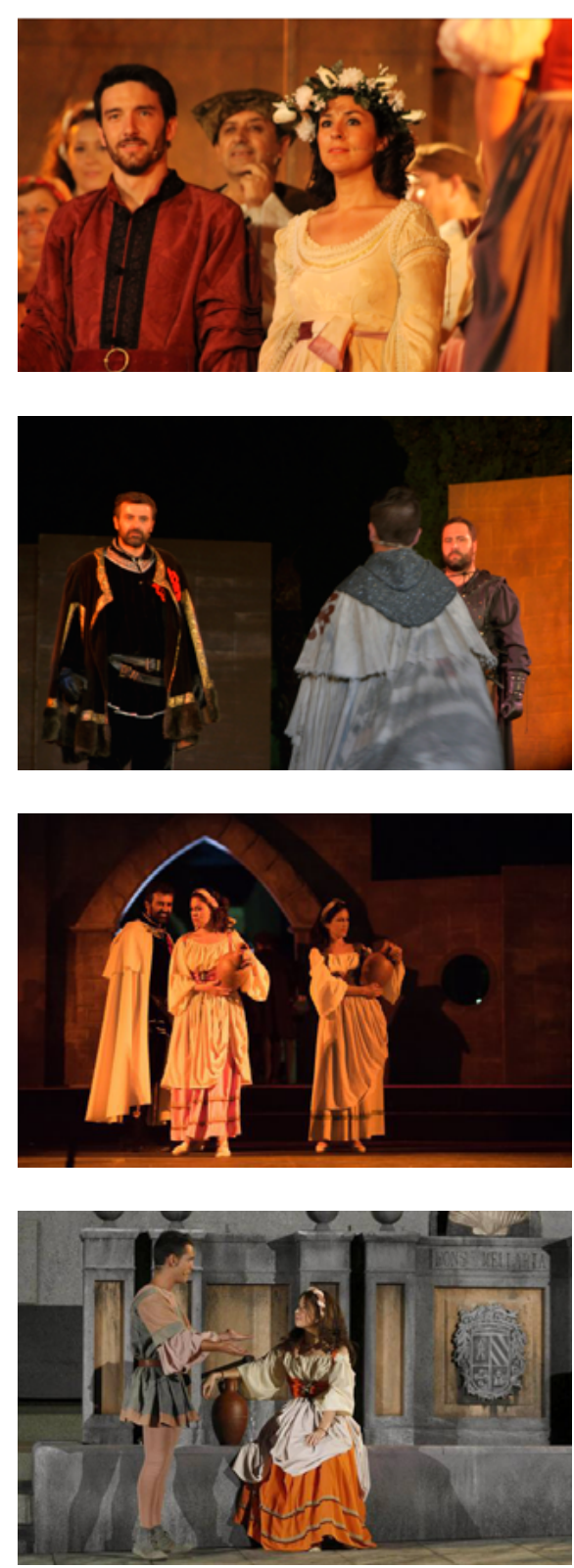

Representación de Fuenteovejuna en años distintos | fotos (de arriba a abajo): 2015 (Ana Ortiz); 2015 los habitantes de Fuente Obejuna ponen en escena su obra en el 38 Festival Internacional de Almagro (Joaquin Alejandre); 2015, en Fuente Obejuna (Guillermo Casas); 2013 (Manolo Blanca) aldeas, ponderando la cooperación entre las artes y las instituciones como único medio de conseguir una acorde armonía de los elementos integradores de la cultura (GAHETE, 1984: 7). Como parte del programa de aquel primer certamen, dirigido a los grupos de teatro de los institutos de enseñanza secundaria de la provincia de Córdoba, se estrenaba en Fuente Obejuna la obra Cristal de mariposas de Manuel Gahete, que había obtenido en 1983 el Primer Premio Nacional de Teatro Barahona de Soto, representado por el grupo La Charrúa, del que era director Ángel Luis Martín, quien interpretaba además el personaje principal de la obra.

Proclamaba García Lorca que "el teatro es uno de los más expresivos y útiles instrumentos para la edificación de un país y el barómetro que marca su grandeza o su descenso (...) Un pueblo que no ayuda y no fomenta su teatro, si no está muerto, está moribundo" (2014). Ciertamente Fuente Obejuna ha cumplido y cumple con esta enseña sabia demostrando estar al nivel de prestigio que le confirió Lope de Vega y en su ser radica una fuerza dramática interior que no puede desaprovecharse. En las mujeres y hombres de Fuente Obejuna surte una fuerza feraz que nos remite a la leyenda, una savia fructífera que nos sitúa en el vértice, en el eje, en el foco y en el centro del teatro en Córdoba y Andalucía. En el restricto espacio del municipio han convivido dos grupos de teatro con madera de héroes, vocacionales actores de la vieja y nueva casta, directores sin escuela pero inflamados de mágica intuición y de emoción desaforada, hasta algún autor de teatro y, sobre todo, un público devoto que vive y ama el teatro (GAHETE, 1988: 12-14).

Hemos pedido por activa y pasiva, colectiva e individualmente, que la obra Fuenteovejuna, representada periódicamente en el pueblo de Fuente Obejuna, con un elenco completo integrado por melarienses, sea declarada -por su intrínseco valor, su vigente actualidad y su inconmensurable pulsión mediática- bien de interés turístico de Andalucía, lo que permitiría ir colectando toda la documentación que sobre la obra que sigue repartida por el mundo; se consolidaría como sede del teatro clásico en la confluencia de Mérida y Almagro, potenciando las relaciones entre Extremadura, Andalucía y Castilla; y reportaría riqueza económica y promoción de nuestra tierra, plena de tradiciones teatrales que es preciso potenciar. $Y$ no solo porque representa el ideal más álgido de la unión de los débiles contra la tiranía de los poderosos, condicionada según qué convenciones por interpretaciones contrapuestas, sino porque en sí misma la obra merece el reconocimiento universal de su valor poético y su vigor dramático. Y, en esto, ha sido concluyente el impulso decidido del concejo y el pueblo de Fuente Obejuna, que sigue recreando y reviviendo con intensa autenticidad los hechos que, universalizándonos, también nos inmortalizan. 


\section{BIBLIOGRAFÍA}

- ALDEKOA, R. (2016) Del teatro como insumisión [reseña del libro El teatro político de E. Piscator] En Editorial Hiru <http://www.hiru-ed.com/COLECCIONES/SKENE/Elteatro-politico.htm> [Consulta: 22/06/2016]

- AMEzCuA, M. (1991) El ciego de los romances y la literatura de cordel en la tradición jiennense. Revista de Folklore, n. ${ }^{\circ}$ 127, 1991 <http://www.funjdiaz.net/ folklore/06sumario.php?num=127> [Consulta: 2/09/2016]

- FERNÁNDEZ NARANJO, A. (2004) Fuenteovejuna lo hizo. Fuente Obejuna: Ayuntamiento de Fuente Obejuna, 2004

- FROLDI, R. (ed.) (2002) Introducción a Lope de Vega, Fuenteovejuna. Biblioteca Virtual Miguel de Cervantes, 2002 $<$ http://www.cervantesvirtual.com/obra-visor/introduccina-lope-de-vega-fuenteovejuna-0/html/ff2c7cf6-82b1-11dfacc7-002185ce6064_1.htm> [Consulta: 2/09/2016]

- GAHETE, M. (1985) I Certamen de Teatro Fuenteovejuna. Fuente Abejuna, boletín informativo municipal, año I, n. ${ }^{\circ} 8$, 1985

- GAHETE, M. (1988) Siempre Fuente Obejuna, siempre el teatro. Revista Fons Mellaria, n. ${ }^{\circ} 25$, agosto 1988, pp. 12-14

- GARCíA LORCA, F. (2014) Charla sobre el teatro (Conferencia pronunciada en la madrugada del 1 de febrero de 1935 en el Teatro Español). Edición facsímil. Fuente Vaqueros (Granada): Museo Casa Natal Federico García Lorca, 2014

- HERRERAS, E. (2009) La tragedia y los orígenes del teatro político. Cuadernos del Ateneo, n. ${ }^{\circ}$ 27, 2009, pp. 9-18

- MARTínEZ BJORKMAN, J. (1996) Fuenteovejuna: El teatro político. En Actas de las Primeras Jornadas de la Real Academia de Córdoba en Fuente Obejuna. Córdoba: Diputación de Córdoba, 1996, pp. 143-146

- MENÉNDEZ PELAYO, M. (ed.) (1899) Fuenteovejuna de Lope de Vega. Madrid: Real Academia Española, 1899

- VEGA, LOPE DE (2002) Fuenteovejuna. En Dozena Parte de las Comedias de Lope de Vega Carpio (reproducción digital a partir de la edición de la viuda de Alonso Martín, 1619) Alicante: Biblioteca Virtual Miguel de Cervantes; Madrid: Biblioteca Nacional, $2002<$ http:// www.cervantesvirtual.com/obra/fuente-ovejuna-comediafamosa/> [Consulta: 2/09/2016] 